\title{
Affective Priming in Visual-field Superiority
}

\author{
Anamitra Basu (Corresponding author) \\ Department of Humanities, Social Sciences\& Management, Indian Institute of Technology - Bhubaneswar \\ Bhubeneswar, 751013, Orissa, India \\ Tel: 91-674-257-6151 \\ E-mail: anamitra@iitg.ernet.in, anamitrabasu_2@yahoo.co.in; anamitrabasu@iitbbs.ac.in
}

Manas K Mandal

Defence Institute of Psychological Research, Defence R\&D Organization, Ministry of Defence

Lucknow Road, Timarpur, Delhi - 110054, India

Tel: 91-11-2003-2250Ｅ-mail: mkmdipr@yahoo.co.in

\author{
Martial Mermillod \\ Clermont Université
}

LAPSCO-UMR CNRS 6024, 34, Avenue Carnot, 63037 Clermont-Ferrand Cedex, France

Tel: 33-4-7340-6254 E-mail: Martial.Mermillod@univ-bpclermont.fr

\author{
Received: June 17, 2011 Accepted: July 20, $2011 \quad$ Published: December 1, 2011 \\ doi:10.5539/res.v3n2p129 \\ URL: http://dx.doi.org/10.5539/res.v3n2p129
}

\begin{abstract}
The present study aimed at examining the effects of a) stimulus structure, emotional content and presentation mode in eliciting visual-field advantage, and b) priming in eliciting visual-field advantage. Dependent variables in the experiment were recognition accuracy and response latency. Split visual-field paradigm was taken into account. Results using multivariate ANOVA suggested that recognition accuracy of emotional word with exogenous priming was significantly better than that of endogenous priming. Stimuli were significantly better recognized in left visual-field than in right visual-field. Unilaterally, rather than bilaterally, presented stimuli were significantly better recognized. Emotional content were intensely recognized than neutral content.
\end{abstract}

Keywords: Split visual-field, Priming, Recognition accuracy, Visual-field, Presentation mode and stimulus structure and content

\section{Introduction}

An earlier study by the authors (Basu and Mandal, 2004) examined visual-field advantage as a function of stimulus structure and stimulus content and presentation mode. It was found that words were significantly better recognized than faces in right visual-field (RVF) [a function of the left hemisphere], whereas the difference was nonsignificant in left visual-field (LVF) [a function of the right hemisphere]. On the other hand, a LVF advantage was observed in case of emotional content and RVF advantages in case of neutral content. Though the study substantiated the general observation that lexical stimuli are better processed in the RVF than in the LVF while emotional stimuli are better processed in the LVF than in the RVF (see Leventhal and Tomarken, 1986), it was unclear as to how our perceptual field is organized with respect to both affective content (emotional vs. neutral) and visual structure (words vs. faces).

Priming helps in organizing our perceptual field and provides an orientation to perceptual scanning. In other words, it helps in designing the perceptual field of the viewer (Rapp, 2001). Priming at the target stimulus is designated as endogenous, while priming at the central fixation point is designated as exogenous (Rapp, 2001). 
The factor that possibly inhibits right hemisphere superiority in emotion processing is priming. It was found that subjects benefited from summation primes when stimuli were directed to the left visual-field (Beeman, Friedman, Grafman, Perez, Diamond and Lindsey, 1994). Moreover, there was no difference between the two modes of priming for targets projected to the left visual-field, indicating that close and distant associates are activated to a similar degree by right hemisphere activation. Beeman et al. (1994) interpreted that right hemisphere coded information more coarsely than the left hemisphere and this enhanced its ability to activate wider context of a word. Hence, the left hemisphere may have coded emotional words as emotional content contained fineness in itself reducing right hemisphere superiority in emotion processing. According to Lorch (1982), the model of hemispheric language processing predicted that lexical decision time in the left hemisphere should decrease as a function of increasing strength of association between a prime and target word and that in the right hemisphere should be flat. Hence experiments comprising of emotional words of strong association may have inhibited right hemisphere superiority. The finding was strengthened in studies indicating qualitatively distinct patterns of priming in the two hemispheres (Faust and Kahana, 2002). Burt and Perrett (1997) put forward an explanation that right parietal mechanism, involved in control of spatial attention might also be selectively engaged during visual processing, thus causing a bias to scan the left side of all visual stimuli. This suggested that the perceptual bias to the left side of faces did not reflect a right hemisphere specialization for face processing. The study by Rayman and Zaidel (1991) also dealt with linguistic material. These linguistic material was responded consistently more quickly and accurately to right hemi visual-field than that of opposite field.

Motter (2001) opined that visual information follows two major routes for dispersion from primary visual cortex through extrastriate cortex. One route is ventral, which leads to anterior temporal cortex; the other route is dorsal, leading to parietal association cortex. He showed that the sensitivity to visual stimuli along with the effective receptive field size is increased to more than double for parietal visual neurons during an attentive fixation task. However, the receptive fields of inferior temporal cortical neurons collapse around a fixation target under similar conditions.

Rapp (2001) postulated that central cues are cognitive in nature, because they must be interpreted to extract locational information. Peripheral cues, on the other hand, are not cognitive in nature, because they automatically capture attention. Therefore, the cognitive load in central priming (i.e., exogenous priming) is considered to be higher than in peripheral cues (i.e., endogenous priming). Egeth and Yantis (1997) also proposed that central and peripheral cues give rise to different modes of orienting. Other findings, such as Coney (2002), varied the strength of the semantic association between prime and target in a divided visual-field procedure and found that the right hemisphere should exhibit relatively more facilitation than the left in response to weaker associative relationships. On the other hand, the left hemisphere should exhibit relatively more facilitation than the right in the context of stronger relationships. It could, therefore, be presumed that cues, which were cognitive in nature, related to weaker associative strengths. Therefore, exogenous priming would result in less recognition.

Rapp (2001) stated that peripheral cues (endogenous priming in the present study) which are not cognitive in nature, facilitated in perception of stimuli since it captures attention automatically. Although there are some studies on priming, no study has been conducted comparing endogenous and exogenous priming. Judgment feedback has not been intensely studied and the concept of perceptual bias, which is systematic, and simple error, which is random, has not been considered before.

Therefore, these three variables have been treated as between subject factors in the present study.

The present experiment attempted to answer two questions, a) Does priming significantly contribute to the effect on visual-field advantage? b) What form of priming (endogenous, exogenous) elicits visual-field superiority? It was hypothesized that a) priming is a function of visual-field advantage, and b) endogenous priming would elicit greater recognition accuracy as compared to exogenous priming in the split visual-field presentation. A significant interaction is expected between visual -field and priming.

\section{Method}

2.1 Tools

The experiment was based on a personal computer based Java program developed for i) recording personal details of subjects, ii) presenting the items in a controlled way one by one to subjects, iii) recording subject's response. Stimuli were shown through the monitor and responses were saved in database.

\subsection{Design}

The experiment employed univariate ANOVA designs. The design involving Priming was a 2 (Visual-field: left visual-field, right visual-field) x 2 (Presentation mode: unilateral, bilateral) x 2 (Stimulus structure: word, face) $\mathrm{x}$ 
2 (Stimulus content: neutral, emotional) x 2 (Priming: endogenous priming, exogenous priming) mixed factorial design with visual-field, presentation mode, stimulus structure, stimulus content as within subject factors and priming as between subject factor.

\subsection{Sample}

Right handed $(\mathrm{N}=320)$ randomly selected subjects (individual participation) having no visual-field defect with reading habit from "left to right" were chosen for the purpose of the present experiment (mean age $=21.6 \mathrm{yrs}$, $\mathrm{SD}=2.3 \mathrm{yrs}$, mean education $=16.5 \mathrm{yrs}$ engineering students from the Indian Institute of Technology, Kharagpur, India). Subjects were all right-handed as measured by a 20 -item Handedness questionnaire (Mandal, Pandey, Singh, and Asthana, 1992). The average handedness quotient of the group was +. 45 (range $=-1.00$ [left-hander] to +1.00 [right-hander]).

\subsection{Procedure}

\subsubsection{Stimulus material}

Forty-eight photographs depicting facial expressions ( 6 expressions for each of the 6 universal emotions, happy, sad, fear, anger, surprise, disgust $(6 \times 6=36 ; 6$ synonyms of 6 times the identical word written in different font ),and 12 expressions of neutral state) were selected from a set of standard photographs (Mandal, 1987). An identical number of emotion words representing six universal emotions and 12 neutral words were also selected, total $=48$ Preparation of neutral words was made in such a way so that no word exceeded more than 5 letters.

These stimuli were prepared for two modes of presentation: unilateral and bilateral. In each mode of presentation, there were 12 sequences and there were 12 trials in each sequence (total trials $=144$ ) with stimuli counterbalanced for type (face, word), content (emotional, neutral) and visual-field (left, right). Out of 12 trials in each sequence, 6 target stimuli were emotional (3 each in the right visual-field and left visual-field) and 6 stimuli were neutral ( 3 each in the right visual-field and left visual-field). The order of presentation of these trials was randomised using a Bullion Array Method so that no trial appears in succession in the same sequence.

At first, a window appeared on the screen, named 'Start New Test' (first window). The window was designed in a way to record personal details of the subject. After finishing the personal details subjects clicked the icon 'Properties', which opened a new window. The new window contained time delay for image or in other words duration of stimulus material (which can be changed manually, time delay for priming also can be changed manually), sequence number, identification number of the subject. After clicking 'OK' subject clicked the third icon 'Start' and a screen opened. As subject chooses the response category, a window named level 2 opened containing the test stimuli. These stimuli were of the same category, which the subject chooses, in the first step. Stimuli appeared one after another. Each item remained on the screen for duration of $180 \mathrm{msec}$. The second item appeared as soon as the subject responds. After disappearance of last item an icon named 'Result' appeared on the screen. After clicking the icon, a window appears which shows data in tabular as well as in graphical form. Another icon named 'show table' shows data only in tabular form. Subject could abort the test at any point of time by clicking the 'Abort' icon. Data were automatically saved and subject could see their data at the end of the experiment by clicking on the icon named 'see data'. After completion of taking data, second subject gave data in a similar way by pressing 'Start New Test' icon.

\subsubsection{Variables}

Independent Variables: The experiment employed independent variables like visual-field, presentation mode, stimulus structure, stimulus content and priming.

Visual-Field Two visual-fields were employed in the experiment, namely right visual-field (RVF) and left visual-field (LVF).Stimuli were projected to RVF and LVF.

Presentation Mode: Two categories of presentation mode, unilateral and bilateral were employed in the experiment. Under unilateral presentation mode, subjects were shown stimuli only on one side of the visual-field (LVF or RVF). Under bilateral presentation mode, subjects were shown stimuli on both sides of the visual-field (LVF and RVF).

Stimulus Structure: Two types of stimulus structure employed in the experiment were word and face. Stimuli were either a word or a face.

Stimulus Content: Two major types of stimulus contents were employed, namely neutral and emotional.

All these above mentioned factors were treated as within subject variable. Stimuli appeared as a combination of neutral word, neutral face, emotional word, and emotional face. All stimuli were projected to either RVF or LVF (unilateral presentation mode) or RVF and LVF (bilateral presentation mode). 
Priming: Two types of priming, exogenous priming and endogenous priming were employed in the first part of the experiment. Exogenous priming was operationalised as the priming in the centre of the computer monitor (away from the target stimulus); endogenous priming would be appearing in the target place.

Dependent Variables: Dependent variable in the experiment was response accuracy. We assume the response to be accurate only if response is correct in both steps (1 and 2) as described before.

\subsubsection{Task procedure}

The visual-field experiment was conducted using a JAVA based computer program. Four trials consisting of 12 sequences, $(12 \times 4=48$ trials $)$ were given to subjects who used the right index finger for all responses. For correct response, subjects had to identify first by using appropriate arrow keys the stimulus category, i.e (Stimulus structure x Stimulus content), then match the test stimuli with the target stimulus. They were asked to use the arrow keys for giving response in the first step (upward arrow for emotional word, downward arrow for neutral word, leftward arrow for emotional face, rightward arrow for neutral face), then to use the numbers (1-6) on the right side of the monitor according to the test stimuli to match with target stimuli (step 2).

In the experiment subject (sat in front of a 19 inch computer monitor) was told after completing personal details to pay attention on the center of the monitor and priming would appear in the target place (exogenous priming) and in the centre (endogenous priming). After disappearance of priming they were told to pay attention to the presented items and recognize whether they were of category neutral word / neutral face / emotional word / emotional face. Then the subject was told to identify the target stimulus and match the target stimulus from the six stimuli combinations. These test stimuli popped up on the screen as the second window after the subject recognized the stimulus category. Half of the total subjects were exposed to exogenous priming and half to endogenous priming. The stimuli were presented for $180 \mathrm{~ms}$ and the Computer recorded the recognition accuracy in a database. Data were shown both in tabular and graphical form. Only the responses that were correct at both levels were taken into account for computation of results.

\section{Results}

Univariate ANOVA designs involving Priming were employed with a 2 (Visual-field: left visual-field, right visual-field) x 2 (Presentation mode: unilateral, bilateral) x 2 (Stimulus structure: word, face) x 2 (Stimulus content: neutral, emotional) x 2 (Priming: endogenous priming, exogenous priming) mixed factorial design with visual-field, presentation mode, stimulus structure, stimulus content as within subject factors and priming as between subject factor. Findings were analysed for the main effects of Priming and interaction of (Stimulus Structure and Content), Presentation mode (unilateral and bilateral), and Priming were examined.

The summary results of the mean values of recognition accuracy and response latency have been summarized in Table 1.

\subsection{Main Effects of Priming (RA)}

The main effect of Priming was not significant $\mathrm{F}=1.25 \mathrm{df}=1, \mathrm{p}=.264$.The main effects of Visual-Field, Presentation Mode, Stimulus Structure and Stimulus Content were significant. Stimuli were significantly better recognized in $\mathrm{LVF}$ than in $\mathrm{RVF}, \mathrm{F}=213.37, \mathrm{df}=1, \mathrm{p}<.001$. Unilaterally presented stimuli were processed with greater recognition accuracy in comparison to bilaterally presented stimuli, $\mathrm{F}=1285.89, \mathrm{df}=1, \mathrm{p}<.001$. Words were perceived with greater response accuracy than faces, $\mathrm{F}=267.94 \mathrm{df}=1, \mathrm{p}<.001$. Emotional content were more accurately recognized than neutral content, $\mathrm{F}=107.21, \mathrm{df}=1, \mathrm{p}<.001$.

\subsubsection{Three way interaction and two way interaction break ups of priming (RA)}

The three way interaction of Visual-field $x$ Stimulus structure $x$ Priming $F=16.94, d f=1, p<.001$ (figure 1) was reflected in the finding that words were better recognized in LVF in case of exogenous priming than in endogenous priming (figure 1).

[Insert Table 1 here]

The two-way interaction of Visual-Field $x$ Stimulus structure was significant $F=34.68, \mathrm{df}=1, \mathrm{p}<.001$ Recognition accuracy for words in left visual-field (mean=15.7) was higher than face in left visual-field (mean=14.0) as compared to recognition accuracy of these conditions in right visual-field (mean in RVF words= 13.3, mean in RVF face $=12.1$ ).

The two-way interaction of Stimulus Structure $x$ Priming was significant $F=57.59, \mathrm{df}=1, \mathrm{p}<.001$. The two-way interaction of Stimulus Structure $\mathrm{x}$ Priming indicated that words were significantly better recognized in exogenous priming (mean=14.9) than in endogenous priming (mean=14.1). However, face was better recognized in endogenous priming (mean=13.3) than face in exogenous priming (mean=12.8). Moreover recognition 
accuracy in exogenous priming was significantly lower for face as compared to words.

The three-way interaction of Presentation Mode $\mathrm{x}$ Stimulus Structure $\mathrm{x}$ Priming showed that recognition accuracy for exogenous priming was significantly higher in words during bilateral presentation, $\mathrm{F}=56.15, \mathrm{df}=1$, $\mathrm{p}<.001$ (figure 2).

[Insert Table 2 here]

The two-way interaction of Stimulus Structure x Priming confirmed significant difference in recognition of words in exogenous priming that was described earlier.

The three-way interaction of Stimulus Structure x Stimulus content x Priming showed that recognition accuracy of emotional word in exogenous priming was significantly higher than in endogenous priming, $\mathrm{F}=17.25$, $\mathrm{df}=1$, $\mathrm{p}<.001$ (figure 3).

[Insert Figure 3 here].

The two-way interaction of Stimulus Structure $x$ Stimulus Content was also significant, $F=29.02, \mathrm{df}=1, \mathrm{p}<.001$ (figure 4.6). Recognition accuracy for emotional face was however; significantly lower (mean=13.6) than that of emotional word (mean=14.7).

The two- way interaction of Stimulus Content $x$ Priming was significant, $F=15.96$, df $=1,00, p<.001$. Recognition accuracy of neutral contents in exogenous priming (mean=13.4) was lower than neutral contents in endogenous priming (mean=13.5), however that of emotional contents in exogenous priming was significantly higher (mean=14.4) than that of emotional contents in endogenous priming (mean=13.9).

3.1.2 Four way interactions and two way interaction break ups of priming (RA)

The four-way interaction of Visual-Field x Presentation Mode x Stimulus Structure x Priming was significant, $\mathrm{F}$ $=10.74, \mathrm{df}=1, \mathrm{p}<.001$.

The two way interaction of Visual-Field x Structure and Stimulus Structure x Priming was discussed earlier.

he four-way interaction of Visual-Field x Presentation Mode x Stimulus Structure x Stimulus Content was also significant, $\mathrm{F}=11.55, \mathrm{df}=1, \mathrm{p}<.001$.

The two-way interaction of Visual-Field $x$ Stimulus Content was significant $F=209.77, \mathrm{df}=1, \mathrm{p}<.001$ (figure 4.9). Emotional content in LVF was recognized with significant accuracy (mean $=14.92)$ than that of RVF (mean $=13.39)$.

The two way interaction of Visual-Field x Stimulus Structure and Stimulus Structure x Stimulus Content were discussed earlier.

\subsection{Main Effects of Priming (RL)}

Table 1 shows the descriptive data for the dependent measure of response latency. The dependent measure of response latency was considered valid when stimuli were correctly recognized. Response latency for incorrectly recognized stimuli was not considered for analysis.

The main effect of Priming was not significant, $\mathrm{F}=3.55, \mathrm{df}=1, \mathrm{p}=.060$ The main effects of Presentation Mode and Stimulus Structure were significant. (Appendix C.2). Unilaterally presented stimuli were processed more quickly (taking less RL) in comparison to bilaterally presented stimuli, $\mathrm{F}=58.69, \mathrm{df}=1, \mathrm{p}<.001$. Words were quickly perceived than faces, $\mathrm{F}=82.47, \mathrm{df}=1, \mathrm{p}<.001$.

3.2.1 Three way interaction and two way interaction break ups of priming (RL)

Response latency did not elicit any significant interaction with priming factor.

\section{Discussion}

The aim of the present work is to examine the hemispheric advantage as a function of Priming (endogenous, exogenous) in addition with visual-field, stimulus structure and emotional content.

The earlier study by Basu and Mandal (2004) found that words were significantly better recognized than faces in RVF; a LVF advantage was significant in case of emotional content. This study tried to predict further the role of priming in eliciting visual-field advantage as a function of stimulus structure, stimulus content and presentation mode. In this study, the main effects of visual-field, presentation mode, stimulus structure and stimulus content were significant. Stimuli were significantly better recognized in LVF than in RVF; unilaterally presented stimuli were processed with greater recognition accuracy in comparison to bilaterally presented stimuli. Words were perceived with greater response accuracy than faces. Emotional content were more accurately recognized than 
neutral content. This finding is in line with Compton, Feigenson and Widick (2005) that emotional stimuli gets special priority in information processing. Unlike previous study, the present study reflected that words were perceived significantly better recognized in LVF and as a function of priming. This can be corroborated by distinct patterns of priming in the two hemispheres (Faust and Kahana, 2002) and scanning bias (Burt and Perrett, 1997). The main effect of priming as obtained in the present study has not been significant. However, the interaction effects of visual-field $\mathrm{x}$ stimulus structure $\mathrm{x}$ priming are significant. Hence the hypothesis that a) priming is a function of visual-field advantage is rejected and b) endogenous priming would elicit greater recognition accuracy as compared to exogenous priming in the split visual-field presentation is confirmed. This finding corroborates with the study done by Rapp (2001) who showed that the cognitive load in exogenous priming is higher than in endogenous priming(Rapp, 2001). For example, Face is recognized with higher accuracy in both LVF and RVF under endogenous priming than exogenous priming. However, words show higher recognition accuracy under exogenous priming (Stimulus structure X Priming). Likewise, neutral content is recognized with marginally higher accuracy under endogenous priming, while emotional contents have higher recognition accuracy, under exogenous priming (Stimulus Content X Priming).

The findings about stimulus structure against priming are not altered in presence of variation of structure content. Hence, the enunciation of hypothesis that endogenous priming results in higher recognition accuracy is confirmed for the following cases: a) faces for bilateral presentation mode, b) neutral content. The discrepancies between the hypothesis and the results are not unnatural. Although Egeth and Yantis (1997) opined that central and peripheral cues are thought to give rise to different modes of orienting, neuropsychological evidence does not offer full support for different neural mechanisms in exogenous and endogenous priming (Rapp, 2001).

To summarize, it is evident that though main effect of priming was not significant either in recognition accuracy scores, the three-way interaction of Visual-field $\mathrm{x}$ Stimulus structure $\mathrm{x}$ Priming was significant. Words were better recognized in LVF in exogenous priming. Moreover, words were recognized with greater recognition accuracy in LVF. Overall recognition accuracy scores were higher in LVF. This might be due to perceptual bias to scan the left side of all visual stimuli (Burt and Perrett,1997). Words were better recognized in exogenous priming whereas recognition accuracy of faces was better in endogenous priming, and words were better recognized than faces.

\section{Conclusion}

In conclusion, result revealed that endogenous priming elicited higher recognition accuracy for (a) faces, though the effect is more pronounced for bilateral presentation mode, (b) neutral content. The finding that exogenous priming is recognized with greater accuracy than endogenous priming incites interest. Usually endogenous priming captures attention automatically (Rapp, 2001). So superiority of involuntary attention is reversed in the present study. On the other hand, more challenging and complicated task of face perception is achieved automatically. This might be due to the inherent human tendency of capturing complicated tasks more promptly and with greater vigilance.

\section{Implications of this study for future research}

However, the reason behind words being better recognized in exogenous priming and face in endogenous priming could not be substantiated in this work and can be taken up as future research. Although recall of non emotional words were better in the right visual-field than in the left visual-field, recall of positive and negative emotional words did not differ in left and right visual-fields. Thus consideration of valence would have supported the study better.

These issues can therefore be taken into future consideration with sophisticated tool of split visual field task giving due importance to both stimulus structure and content along with valence of stimuli. Dichotic listening measures can also be taken into account to assess the relationship of hemispheric dominance with respect to priming.

\section{References}

Basu, A. and Mandal, M. K. (2004). Brief Communication: visual-field superiority as a function of stimulus type and content: further evidence. International Journal of neuroscience, 114(7), 833-839. http://dx.doi.org/10.1080/00207450490441055

Beeman, M., Friedman, R., Grafman, J., Perez, E., Diamond, S., and Lindsey, M. (1994). Summation priming and coarse semantic coding in the right hemisphere. Journal of cognitive Neuroscience, 6, 26-45. http://dx.doi.org/10.1162/jocn.1994.6.1.26

Burt, D. M. and Perrett, D. I. (1997). Perceptual asymmetries in judgments of facial attractiveness, age, gender, 
speech and expression. Neuropsychologia, 35(5), 685-693. http://dx.doi.org/10.1016/S0028-3932(96)00111-X

Compton, R. J., Feigenson, K. and Widick, P. (2005). Take it to the bridge: An interhemispheric processing advantage for emotional faces. Cognitive Brain Research, 24(1), 66-72. http://dx.doi.org/10.1016/j.cogbrainres.2004.12.002

Coney, J. (2002). The effect of associative strength on priming in the cerebral hemispheres. Brain and Cognition, 50, 234-241. http://dx.doi.org/10.1016/S0278-2626(02)00507-9

Egeth, H. E. and Yantis, S. (1997). Visual attention: Control, representation, and time course. Annual review of psychology, 48(1), 269-297. http://dx.doi.org/10.1146/annurev.psych.48.1.269

Faust, M. and Kahana, A. (2002). Priming summation in the cerebral hemispheres:evidence from semantically convergent and semantically divergent primes. Neuropsychologia, 40(7), 892-901. http://dx.doi.org/10.1016/S0028-3932(01)00174-9

Leventhal, H. and Tomarken, A. J. (1986). Emotion: Today's Problems. Annual Review of Psychology, 37, 565-610. http://dx.doi.org/10.1037/0003-066X.60.5.431

Lorch, R .F. (1982). Priming and search process in semantic memory: A text of three models of spreading activation. Journal of verbal Learning and Verbal Behaviour, 21, 468-492. http://dx.doi.org/10.1016/S0022-5371(82)90736-8

Mandal, M. K. (1987). Decoding of facial emotion in terms of expressiveness by schizophrenics and depressives. Psychiatry: Interpersonal and Biological Processes, 50(4), 371-376.

Mandal, M. K., Pandey, G., Singh, S. K., and Asthana, H. S. (1992). Degree of asymmetry in lateral preferences: eye, foot, ear. Journal of Psychology, 126, 155-162.

Motter, B. (2001). Attention in the animal Brain. In Wilson, R. A., and Keil, F. C. (eds.) The MIT Encyclopaedia of the Cognitive Sciences, 42. MIT Press, Cambridge, Massachusetts, London, England.

Rapp, B. (2001). The handbook of Cognitive Neuropsychology: What deficits reveal about the Human Mind. New York: Psychology Press.

Rayman, J. and Zaidel, E. (1991). Rhyming and the right hemisphere. Brain Language, 40, 89-105. http://dx.doi.org/10.1016/0093-934X(91)90118-K

Schweinberger, S. R., Baird, L. M., Blumler, M., Kauffmann, J. M., and Mohr, B. (2003). Interhemispheric cooperation for face recognition but not for affective facial expressions. Neuropsychologia, 41,407- 414 . http://dx.doi.org/10.1016/S0028-3932(02)00173-2 
Table 1. Mean recognition accuracy and response latency mean and standard deviation (sd) for visual-field,stimulus structure, stimulus content, presentation mode

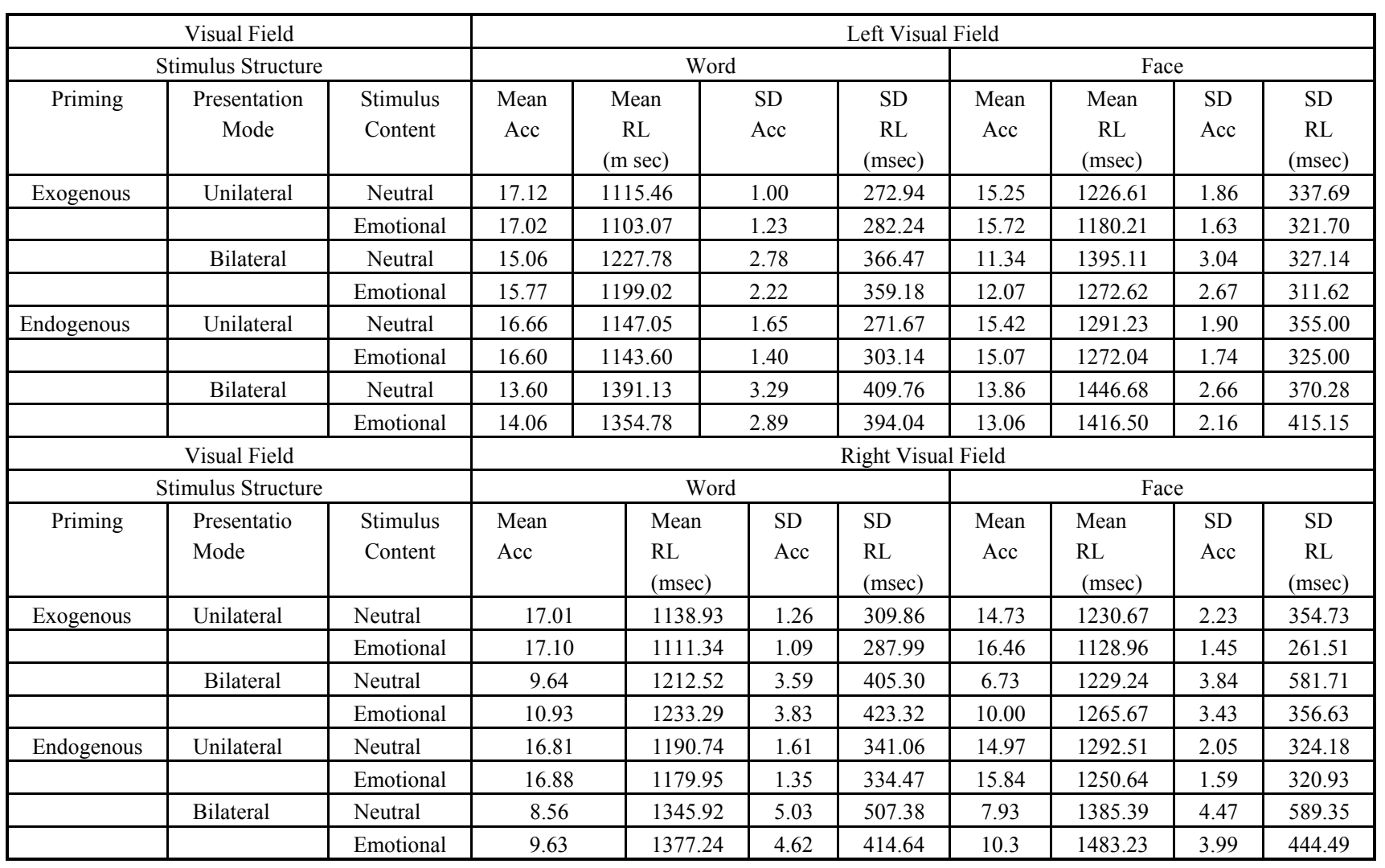

*Maximum possible score per cell: 18 (for Accuracy)

*Response latency is for correct response only 
Table 2. Summary ANOVA with priming recognition accuracy as dependent measure

\begin{tabular}{|c|c|c|c|c|c|}
\hline \multicolumn{6}{|c|}{ Tests of Between-Subjects Effects (Priming Recognition Accuracy) } \\
\hline Source & Sum of Squares & df & Mean Square & $\mathbf{F}$ & Sig \\
\hline PRIMING & 36.113 & 1 & 36.113 & 1.25 & .264 \\
\hline Error & 9168.962 & 318 & 28.833 & & \\
\hline \multicolumn{6}{|c|}{ Tests of Within -Subjects Effects (Priming Recognition Accuracy) } \\
\hline VISUAL-FIELD & 5839.653 & 1 & 5839.653 & 213.37 & .001 \\
\hline VISUAL-FIELD x PRIMING & 2.032 & 1 & 2.032 & .07 & .785 \\
\hline Error (VISUAL-FIELD) & 8702.940 & 318 & 27.368 & & \\
\hline PRESENTATION MODE & 28984.595 & 1 & 28984.595 & 1285.89 & .001 \\
\hline PRESENTATION MODE x PRIMING & 13.203 & 1 & 13.203 & .58 & .445 \\
\hline Error (PRESENTATION MODE) & 7167.827 & 318 & 22.540 & & \\
\hline STRUCTURE & 2808.450 & 1 & 2808.450 & 267.94 & .000 \\
\hline STRUCTURE x PRIMING & 603.626 & 1 & 603.626 & 57.59 & .001 \\
\hline Error (STRUCTURE) & 3333.049 & 318 & 10.481 & & \\
\hline CONTENT & 699.153 & 1 & 699.153 & 107.21 & .001 \\
\hline CONTENT x PRIMING & 104.082 & 1 & 104.082 & 15.96 & .001 \\
\hline Error (CONTENT) & 2073.640 & 318 & 6.521 & & \\
\hline VISUAL-FIELD x PRESENTATION MODE & 6502.520 & 1 & 6502.520 & 222.28 & .001 \\
\hline VISUAL-FIELD x PRESENTATION MODE x PRIMING & 15.753 & 1 & 15.753 & .53 & .464 \\
\hline VISUAL- FIELD x STRUCTUR & 102.378 & 1 & 102.378 & 34.68 & .001 \\
\hline VISUAL-FIELD x STRUCTURE x PRIMING & 50.007 & 1 & 50.007 & 16.94 & .001 \\
\hline Error (VISUAL-FIELD x STRUCTURE) & 938.740 & 318 & 2.952 & & \\
\hline PRESENTATION MODE x STRUCTURE & .282 & 1 & .282 & .03 & .860 \\
\hline PRESENTATION MODE x STRUCTURE x PRIMING & 510.050 & 1 & 510.050 & 56.15 & .001 \\
\hline Error (PRESENTATION MODE x STRUCTURE) & 2888.293 & 318 & 9.083 & & \\
\hline VISUAL-FIELD x PRESENTATION MODE x STRUCTURE & 89.782 & 1 & 89.782 & 33.48 & .001 \\
\hline $\begin{array}{l}\text { VISUAL-FIELD x PRESENTATION MODE x STRUCTURE } \mathrm{x} \\
\text { PRIMING }\end{array}$ & 28.800 & 1 & 28.800 & 10.74 & .001 \\
\hline $\begin{array}{lllll}\text { Error (VISUAL-FIELD } & \mathrm{x} & \text { PRESENTATION } & \text { MODE } & \mathrm{x} \\
\text { STRUCTURE) } & & & & \\
\end{array}$ & 852.543 & 318 & 2.681 & & \\
\hline VISUAL-FIELD x CONTENT & 465.613 & 1 & 465.613 & 209.77 & .001 \\
\hline VISUAL-FIELD x CONTENT x PRIMING & 1.445 & 1 & 1.445 & .65 & .420 \\
\hline Error (VISUAL-FIELD x CONTENT) & 705.818 & 318 & 2.220 & & \\
\hline PRESENTATION MODE x CONTENT & 205.601 & 1 & 205.601 & 68.55 & .001 \\
\hline PRESENTATION MODE x CONTENT x PRIMING & 7.503 & 1 & 7.503 & 2.50 & .115 \\
\hline Error (PRESENTATION MODE x CONTENT) & 953.771 & 318 & 2.999 & & \\
\hline VISUAL-FIELD x PRESENTATION MODE x CONTENT & 85.595 & 1 & 85.595 & 31.36 & .001 \\
\hline $\begin{array}{l}\text { VISUAL-FIELD } \mathrm{x} \text { PRESENTATION MODE } \mathrm{x} \text { CONTENT } \mathrm{x} \\
\text { PRIMING }\end{array}$ & 3.003 & 1 & 3.003 & 1.10 & .295 \\
\hline Error (VISUAL-FIELD x PRESENTATION MODE x CONTENT) & 867.777 & 318 & 2.729 & & \\
\hline STRUCTURE X CONTENT & 112.813 & 1 & 112.813 & 29.02 & .001 \\
\hline STRUCTURE $\mathrm{x}$ CONTENT $\mathrm{x}$ PRIMING & 67.070 & 1 & 67.070 & 17.25 & .001 \\
\hline Error (STRUCTURE x CONTENT) & 1235.993 & 318 & 3.887 & & \\
\hline VISUAL-FIELD x STRUCTURE x CONTENT & 222.778 & 1 & 222.778 & 99.98 & .001 \\
\hline VISUAL-FIELD x STRUCTURE X CONTENT $\quad$ x PRIMING & 2.032 & 1 & 2.032 & .91 & .340 \\
\hline Error (VISUAL-FIELD x STRUCTURE x CONTENT) & 708.565 & 318 & 2.228 & & \\
\hline PRESENTATION MODE x STRUCTURE x CONTENT & 2.195 & 1 & 2.195 & .68 & .410 \\
\hline $\begin{array}{l}\text { PRESENTATION MODE } \mathrm{x} \text { STRUCTURE } \mathrm{x} \text { CONTENT } \mathrm{x} \\
\text { PRIMING }\end{array}$ & .253 & 1 & .253 & .07 & .780 \\
\hline Error (PRESENTATION MODE x STRUCTURE x CONTENT) & 1025.427 & 318 & 3.225 & & \\
\hline $\begin{array}{l}\text { VISUAL-FIELD x PRESENTATION MODE x STRUCTURE } \mathrm{x} \\
\text { CONTENT }\end{array}$ & 27.907 & 1 & 27.907 & 11.55 & .001 \\
\hline $\begin{array}{l}\text { VISUAL-FIELD } \mathrm{x} \text { PRESENTATION MODE } \mathrm{x} \text { STRUCTURE } \mathrm{x} \\
\text { CONTENT } \mathrm{x} \text { PRIMING }\end{array}$ & 1.653 & 1 & 1.653 & .68 & .409 \\
\hline $\begin{array}{lllll}\text { Error (VISUAL-FIELD } \quad \mathrm{x} & \text { PRESENTATION } & \text { MODE } & \mathrm{x} \\
\text { STRUCTURE x CONTENT) } & & & \\
\end{array}$ & 768.315 & 318 & 2.416 & & \\
\hline
\end{tabular}


Table 3. Summary ANOVA with priming response latency as dependent measure

\begin{tabular}{|c|c|c|c|c|c|}
\hline \multicolumn{6}{|c|}{ Tests of Between-Subjects Effects (Priming Response Latency) } \\
\hline Source & Sum of Squares & df & Mean Square & $\mathbf{F}$ & Sig \\
\hline Priming & 14418567.112 & 1 & 14418567.112 & 3.55 & .060 \\
\hline Error & 1289481123 & 318 & 4054972.086 & & \\
\hline \multicolumn{6}{|c|}{ Tests of Within-Subjects Effects } \\
\hline VISUAL-FIELD & 80232.778 & 1 & 80232.778 & 1.62 & .204 \\
\hline VISUAL-FIELD x PRIMING & 224375.632 & 1 & 224375.632 & 4.53 & .034 \\
\hline Error (VISUAL-FIELD) & 15718211.965 & 318 & 49428.340 & & \\
\hline PRSENTATION MODE & 24933957.188 & 1 & 24933957.188 & 58.69 & .001 \\
\hline PRSENTATION MODE x PRIMING & 2004236.328 & 1 & 2004236.328 & 4.71 & .031 \\
\hline Error (PRSENTATION MODE) & 135089567.859 & 318 & 424809.962 & & \\
\hline STRUCTURE & 8391763.188 & 1 & 8391763.188 & 82.47 & .001 \\
\hline STRUCTURE $\mathrm{x}$ PRIMING & 72150.078 & 1 & 72150.078 & .70 & .400 \\
\hline Error (STRUCTURE) & 32356952.109 & 318 & 101751.422 & & \\
\hline CONTENT & 434608.903 & 1 & 434608.903 & 5.80 & .017 \\
\hline CONTENT $\mathrm{x}$ PRIMING & 363050.195 & 1 & 363050.195 & 4.85 & .028 \\
\hline Error (CONTENT) & 23803287.777 & 318 & 74853.106 & & \\
\hline Error (CONTENT) & 23803287.777 & 318 & 74853.106 & & \\
\hline VISUAL-FIELD x PRSENTATION MODE & 232309.013 & 1 & 232309.013 & 4.42 & .036 \\
\hline VISUAL-FIELD x PRSENTATION MODE x PRIMING & 18688.970 & 1 & 18688.970 & .35 & .551 \\
\hline Error (VISUAL-FIELD x PRSENTATION MODE) & 16679181.893 & 318 & 52450.258 & & \\
\hline VISUAL-FIELD x STRUCTURE & 587216.450 & 1 & 587216.450 & 13.07 & .001 \\
\hline VISUAL-FIELD x STRUCTURE x PRIMING & 197582.351 & 1 & 197582.351 & 4.39 & .037 \\
\hline Error (VISUA-FIELD x STRUCTURE) & 14283668.074 & 318 & 44917.195 & & \\
\hline PRSENTATION MODE x STRUCTURE & 180428.757 & 1 & 180428.757 & 3.34 & .068 \\
\hline PRSENTATION MODE x STRUCTURE x PRIMING & 152644.128 & 1 & 152644.128 & 2.82 & .094 \\
\hline Error (PRSENTATION MODE x STRUCTURE) & 17161878.490 & 318 & 53968.171 & & \\
\hline VISUAL-FIELD x PRSENTATION MODE x STRUCTURE & 1193.512 & 1 & 1193.512 & .02 & .873 \\
\hline $\begin{array}{l}\text { VISUAL-FIELD x PRSENTATION MODE x STRUCTURE } \\
\mathrm{x} \text { PRIMING }\end{array}$ & 291037.970 & 1 & 291037.970 & 6.19 & .013 \\
\hline $\begin{array}{l}\text { Error (VISUAL-FIELD x PRSENTATION MODE x } \\
\text { STRUCTURE) }\end{array}$ & 14942414.893 & 318 & 46988.726 & & \\
\hline VISUAL-FIELD x CONTENT & 460978.657 & 1 & 460978.657 & 9.163 & .003 \\
\hline VISUAL-FIELD x CONTENT x PRIMING & 3850.313 & 1 & 3850.313 & .07 & .782 \\
\hline Error (VISUAL-FIELD x CONTENT) & 15999009.905 & 318 & 50311.352 & & \\
\hline PRSENTATION MODE x CONTENT & 269062.003 & 1 & 269062.003 & 5.60 & .019 \\
\hline PRSENTATION MODE x CONTENT x PRIMING & 9630.563 & 1 & 9630.563 & .20 & .655 \\
\hline Error (PRSENTATION MODE x CONTENT) & 15273853.309 & 318 & 48030.985 & & \\
\hline VISUAL-FIELD x PRSENTATION MODE x CONTENT & 1273673.538 & 1 & 1273673.538 & 23.85 & .001 \\
\hline $\begin{array}{l}\text { VISUAL-FIELD x PRSENTATION MODE x CONTENT x } \\
\text { PRIMING }\end{array}$ & 14177.813 & 1 & 14177.813 & .26 & .607 \\
\hline $\begin{array}{l}\text { Error (VISUAL-FIELD x PRSENTATION MODE x } \\
\text { CONTENT) }\end{array}$ & 16981235.024 & 318 & 53400.110 & & \\
\hline STRUCTURE x CONTENT & 128560.612 & 1 & 128560.612 & 2.05 & .152 \\
\hline STRUCTURE $\mathrm{x}$ CONTENT $\mathrm{x}$ PRIMING & 224852.520 & 1 & 224852.520 & 3.59 & .059 \\
\hline Error (STRUCTURE x CONTENT) & 19870847.743 & 318 & 62486.943 & & \\
\hline VISUAL-FIELD $\mathrm{x}$ STRUCTURE $\mathrm{x}$ CONTENT & 65308.163 & 1 & 65308.163 & 1.41 & .236 \\
\hline VISUAL-FIELD x STRUCTURE x CONTENT x PRIMING & 2946.378 & 1 & 2946.378 & .06 & .801 \\
\hline Error (VISUAL-FIELD x STRUCTURE x CONTENT) & 14714189.834 & 318 & 46271.037 & & \\
\hline PRSENTATION MODE x STRUCTURE x CONTENT & 111863.403 & 1 & 111863.403 & 2.18 & .141 \\
\hline $\begin{array}{l}\text { PRSENTATION MODE } x \text { STRUCTURE } x \text { CONTENT } x \\
\text { PRIMING }\end{array}$ & 40017.695 & 1 & 40017.695 & .78 & .378 \\
\hline $\begin{array}{llll}\text { Error (PRSENTATION } & \text { MODE } & \mathrm{x} & \text { STRUCTURE } \\
\text { CONTENT) }\end{array}$ & 16306551.777 & 318 & 51278.465 & & \\
\hline $\begin{array}{lcccc}\text { VISUAL-FIELD } & \mathrm{x} & \text { PRSENTATION } & \text { MODE } & \mathrm{x} \\
\text { STRUCTURE } \mathrm{x} \text { CONTENT } & & & \end{array}$ & 253547.051 & 1 & 253547.051 & 5.88 & .016 \\
\hline $\begin{array}{l}\text { VISUAL-FIELD } \mathrm{x} \text { PRSENTATION } \mathrm{x} \text { STRUCTURE } \mathrm{x} \\
\text { CONTENT } \mathrm{x} \text { PRIMING } \\
\end{array}$ & 27232.200 & 1 & 27232.200 & .63 & .427 \\
\hline $\begin{array}{llllll}\text { Error (VISUAL-FIELD } & \mathrm{x} & \text { PRSENTATION } & \text { MODE } & \mathrm{x} \\
\text { STRUCTURE } \mathrm{x} & & & & & \\
\text { CONTENT) } & & & & \\
\end{array}$ & 13695333.624 & 318 & 43067.087 & & \\
\hline
\end{tabular}




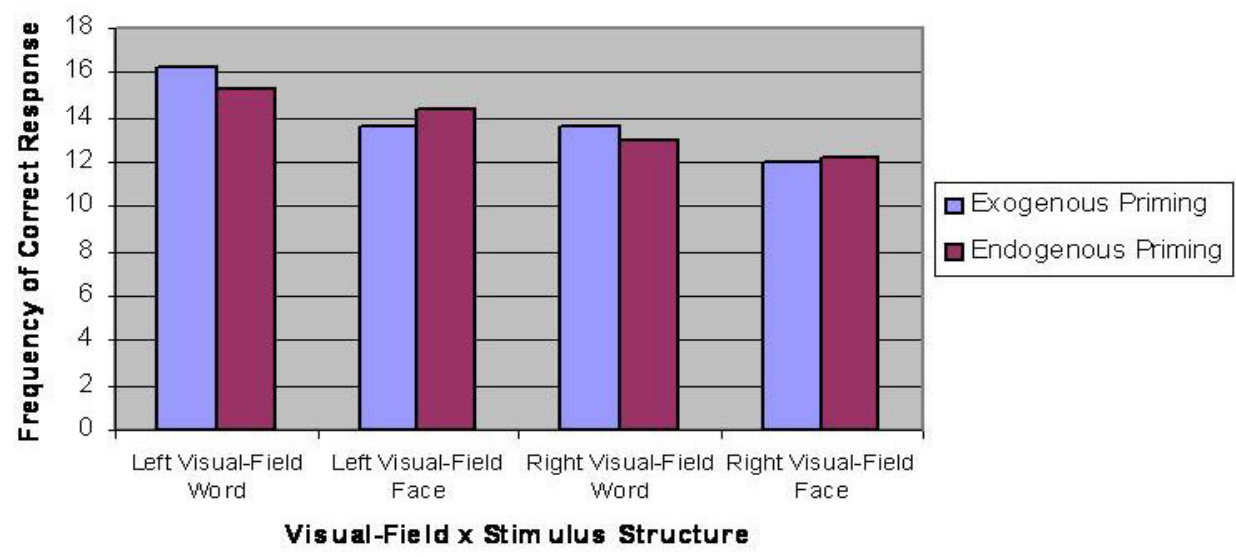

Figure 1. The Three Way Interaction of Visual-Field X Stimulus Structure X Priming

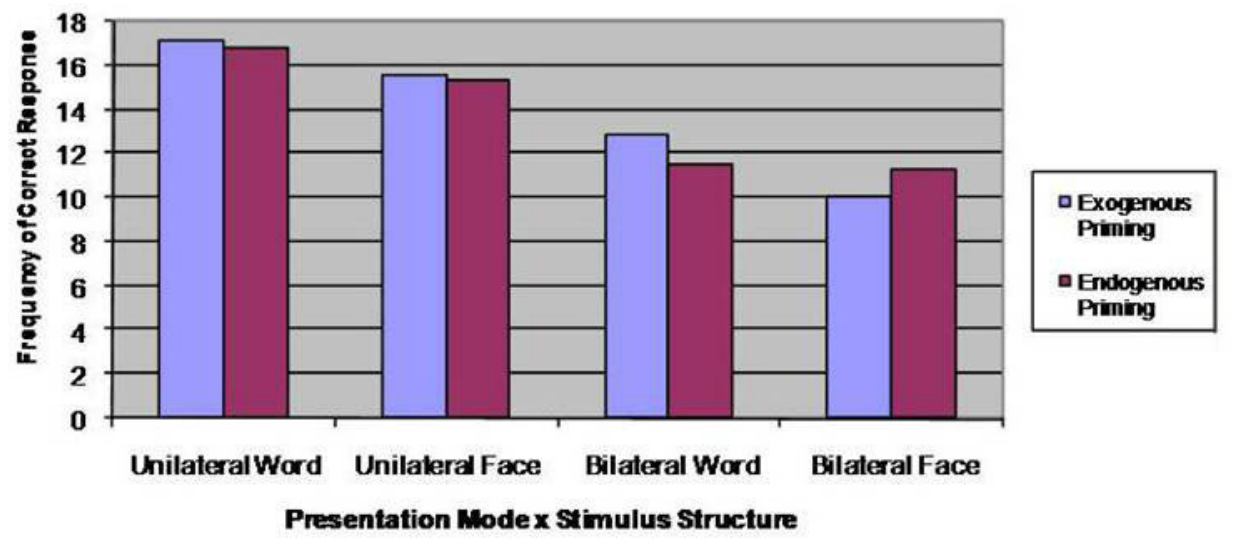

Figure 2. The Three-Way Interaction of Presentation Mode X Stimulus Structure X Priming

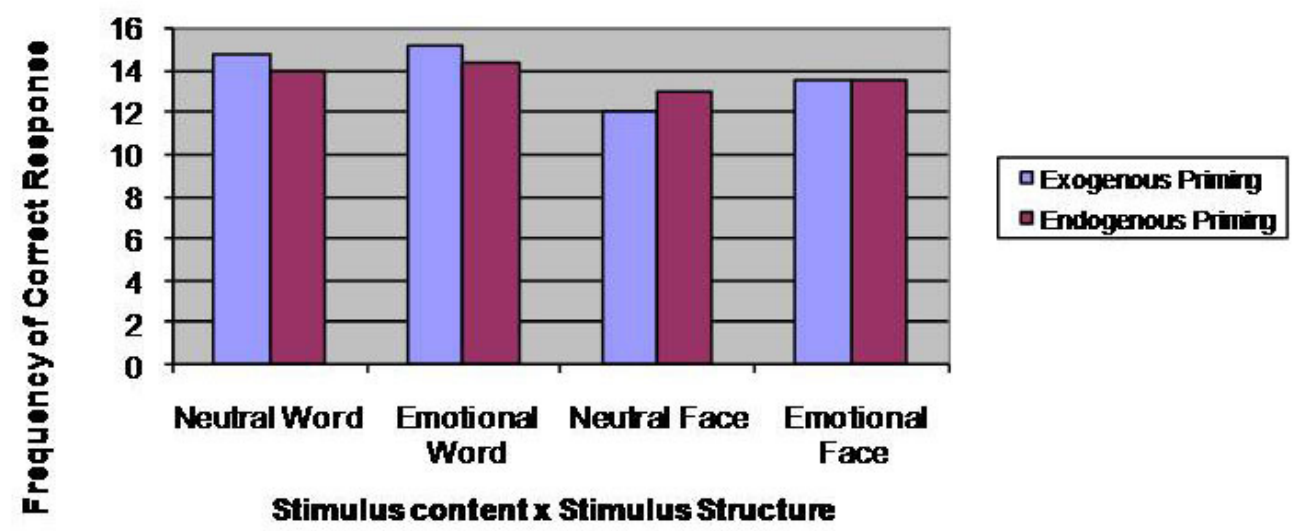

Figure 3. The Three-Way Interaction of Stimulus Structure X Stimulus Content X Priming 